\title{
The Switch of Subthalamic Neurons From an Irregular to a Bursting Pattern Does Not Solely Depend on Their GABAergic Inputs in the Anesthetic-Free Rat
}

\author{
Nadia Urbain, ${ }^{1}$ Nicolas Rentéro, ${ }^{1}$ Damien Gervasoni, ${ }^{2}$ Bernard Renaud, ${ }^{1}$ and Guy Chouvet ${ }^{1}$ \\ ${ }^{1}$ Laboratoire de Neuropharmacologie et Neurochimie, Institut National de la Santé et de la Recherche Médicale U512, \\ Université Claude-Bernard-Lyon 1, 69373 Lyon, France, and 2Department of Neurobiology, Duke University Medical \\ Center, Durham, North Carolina 27710
}

The subthalamic nucleus (STN) powerfully controls basal ganglia outputs and has been implicated in movement disorders observed in Parkinson's disease because of its pathological mixed burst firing mode and hyperactivity. A recent study suggested that reciprocally connected glutamatergic STN and GABAergic globus pallidus (GP) neurons act in vitro as a generator of bursting activity in basal ganglia. In vivo, we reported that GP neurons increased their firing rate in wakefulness (W) compared with slow-wave sleep (SWS) without any change in their random pattern. In contrast, STN neurons exhibited similar firing rates in W and SWS, with an irregular pattern in W and a bursty one in SWS. Thus, the pallidal GABAergic tone might control the STN pattern. This hypothesis was tested by mimicking such variations with microiontophoresis of GABA receptor ligands. GABA agonists specifically decreased the STN firing rate but did not affect its firing pattern. $G A B A_{A}$ (but not $G_{A B A}$ ) antagonists strongly enhanced the STN mean discharge rate during all vigilance states up to three to five times its basal activity. However, such applications did not change the typical $W$ random pattern. When applied during SWS, $\mathrm{GABA}_{\mathrm{A}}$ antagonists strongly reinforced the spontaneous bursty pattern into a particularly marked one with instantaneous frequencies reaching $500-600 \mathrm{~Hz}$. SWS-W transitions occurring during ongoing antagonist iontophoresis invariably disrupted the bursty pattern into a random one. Thus $\mathrm{GABA}_{\mathrm{A}}$ receptors play a critical, but not exclusive, role in regulating the excitatory STN influence on basal ganglia outputs.

Key words: subthalamic nucleus; GABA; bicuculline; gabazine; extracellular single-unit recordings; firing pattern; bursts of spikes; nonanesthetized animal; sleep-wake cycle; microiontophoresis
The subthalamic nucleus (STN) plays a critical role in the control of movement by virtue of its glutamatergic projections to the basal ganglia output nuclei, which in turn innervate the thalamus and subcortical premotor areas (Albin et al., 1989; DeLong, 1990). Indeed, previous studies have demonstrated that a large proportion of STN neurons discharge high-frequency bursts related to movements (DeLong et al., 1985; Matsumura et al., 1992; Wichmann et al., 1994a; Cheruel et al., 1996). Furthermore, abnormal activity of the STN has been shown to be implicated in the parkinsonian motor symptoms (Bergman et al., 1990; DeLong, 1990; Wichmann et al., 1994b) and in the generation of involuntary hemiballistic movements (Hammond et al., 1979; Crossman et al., 1980, 1984; Beurrier et al., 1997). Several lines of evidence support an elevated discharge rate and a preponderant bursty pattern of STN neurons in experimental models of Parkinson's disease (PD; Bergman et al., 1994, 1998; Benazzouz et al., 1996; Hassani et al., 1996; Périer et al., 2000; Vila et al., 2000). More-

\footnotetext{
Received Dec 5, 2001; revised June 27, 2002; accepted June 28, 2002.

This work was supported by grants from Institut National de la Santé et de la Recherche Médicale, Fondation pour la Recherche Médicale (FRM), Université Claude Bernard-Lyon 1, and Conseil Régional Rhône-Alpes. N.U. was the recipient of fellowships from the Région Rhône-Alpes and the FRM (Neuroscience Research programs). We thank Thierry Duffau for efficient computational expertise and Lydie Ferres, Margaret Pras, and Geneviève Deguilhem for administrative assistance. We also thank Vincent Santucci for providing SR-95531 and Christophe Dugast, Nathalie Javelle, Corinne Beurrier, and Constance Hammond for helpf ul assistance.

Correspondence should be addressed to Guy Chouvet, Laboratoire de Neuropharmacologie et Neurochimie, Institut National de la Santé et de la Recherche Médicale U512, Université Claude-Bernard-Lyon 1, 69373 Lyon, France. E-mail: gchouvet@rockefeller.univ-lyon1.fr.

Copyright (ㄷ) 2002 Society for Neuroscience $0270-6474 / 02 / 228665-11 \$ 15.00 / 0$
}

over, some STN cells exhibit a rhythmic activity strictly correlated with tremor in limbs of parkinsonian patients, suggesting that STN might be implicated in the PD tremor (Rodriguez et al., 1998; Levy et al., 2000; Magariñoz-Ascone et al., 2000).

Although much progress has been made in understanding the intrinsic properties of STN neurons, the fact that in vitro these neurons fire spontaneously with a tonic discharge of single spikes only (Nakanishi et al., 1987; Overton and Greenfield, 1995; Bevan and Wilson, 1999; Bevan et al., 2002) (but see also Beurrier et al., 1999), whereas in vivo they exhibit a more or less regular or bursty pattern in anesthetized preparations (Hollerman and Grace, 1992; Ryan et al., 1992; Hassani et al., 1996; Kreiss et al., 1997; Magill et al., 2000), suggests that STN afferents play a crucial role in the modulation of its firing pattern.

Plenz and Kitai (1999), using a simplified culture system in vitro, proposed that reciprocally connected glutamatergic STN and GABAergic globus pallidus (GP) neurons form an oscillating feedback system that might act as the central tremor generator in PD. By contrast, in vivo we have shown recently that STN neuronal activity could spontaneously shift from a more or less regular discharge in wakefulness (W) to a bursty pattern in slow-wave sleep (SWS) but without related changes in the GP firing pattern (Urbain et al., 2000). Nevertheless, the GP mean firing rate was lower in SWS than in W. Changes in the GP rate might thus result in changes in the STN pattern, as suggested previously by lesions thought to mimic increased or decreased levels of the GABAergic GP tone on STN neurons (Ryan et al., 1992). According to this hypothesis, we have tested, across the sleep-wake cycle, whether it was possible to regularize bursty 
STN neurons by microiontophoresis of GABA agonists (to mimic an increased W-GP tone), or inversely to induce bursts on more or less regular neurons by GABA antagonists (to mimic a decreased SWS-GP tone).

\section{MATERIALS AND METHODS}

Fixation of the head-restraining system. Male Sprague Dawley rats (280320 gm; IFFA Credo, Arbresle, France) were anesthetized with chloral hydrate $\left(400 \mathrm{mg} / \mathrm{kg}\right.$, i.p., supplemented with $120 \mathrm{mg} \cdot \mathrm{kg}^{-1} \cdot \mathrm{hr}^{-1}$, i.p., via a perfusion pump) and positioned conventionally (i.e., with ear and nose bars) in a stereotaxic apparatus (Unimécanique, Epinay-sur-Seine, France). Body temperature was monitored and maintained at $37-38^{\circ} \mathrm{C}$ with an electric heating pad. The skull was exposed and carefully cleaned with citric acid $(5 \%, \mathrm{w} / \mathrm{v})$. Three stainless steel screws were implanted over the parietal areas of the skull, and three steel flexible wires inserted into the neck muscles for standard monitoring of the electroencephalogram (EEG) and electromyogram (EMG), respectively. The bone was then covered with a thin layer of acrylic cement (Superbond; Sun Medical Co., Moriyama, Shiga, Japan), except the region overlying the STN and the bregma suture (stereotaxic reference point). A U-shaped piece of aluminum, fixed to a flexible carriage (GFG Co., Pierre-Bénite, Rhône, France) fastened to the stereotaxic apparatus was positioned above the STN. This U-shaped piece was then embedded in dental cement with the EEG screws and EMG wires and their six-pin connector, leaving a well inside the U-shaped piece that was closed with bone wax, as described previously (Darracq et al., 1996; Gervasoni et al., 1998, 2000; Soulière et al., 2000). This U-shaped piece later allowed painless head restraint of the rat. The animal was then removed from the stereotaxic apparatus and allowed to recover from surgery and anesthesia for $48 \mathrm{hr}$ before the habituation sessions began. The U-shaped piece $(\sim 5 \mathrm{gm})$ was well tolerated by the rats, which were able to move, sleep, feed, and drink normally in their home cage. All experiments were performed with the approval of the Regional Animal Care Committee (Université Claude Bernard-Lyon 1) and the French Ministry of Agriculture (legal authorization number 03-505), in accordance with the appropriate European Communities Council directive (86/609/EEC), and complied with rules set forth in the National Institutes of Health Guide for the Care and Use of Laboratory Animals (publication 80-23). All animals were housed in standard conditions $\left(21 \pm 1^{\circ} \mathrm{C}\right.$, food and water ad libitum $)$, and all experiments were performed during the light part of the cycle $(12 \mathrm{hr}$ light/dark cycle).

Habituation of rats to the head-restraining frame. During 8-10 successive days, repetitive trials of increasing duration were performed to train the rats to stay in the restraining frame. Their heads were painlessly secured to the stereotaxic frame by screwing the U-shaped piece, cemented to the rat's head, with its associated carriage; their bodies were lying comfortably in a hammock. At the end of the training period, they could stay calm for periods of 5-6 hr during which quiet W, SWS, and short-lasting paradoxical sleep (PS) episodes were typically observed, attesting that the restraint was well tolerated, as described previously (Gervasoni et al., 1998, 2000; Soulière et al., 2000; Urbain et al., 2000).

Single-unit and polygraphic recordings. After the 8-10 d of habituation and before the first single-unit recording session, rats were anesthetized with chloral hydrate $(320 \mathrm{mg} / \mathrm{kg}$, i.p., additional doses as needed, i.p.), and a $4 \mathrm{~mm}$ trephine hole was drilled over the STN. The dura matter was then removed, and the well was closed as described above. After $1 \mathrm{~d}$ of recovery, daily recording sessions were typically performed over a maximum of $7-10 \mathrm{~d}$, each session lasting $\sim 4-6 \mathrm{hr}$. The brain surface was cleaned under local lidocaine anesthesia at the beginning of each daily recording session.

Extracellular recordings of STN neurons were performed using singlebarrel glass micropipettes (external tip diameter, 2-3 $\mu \mathrm{m}$ ) filled with $2 \%$ pontamine sky blue in sodium acetate $(0.5 \mathrm{M}, \mathrm{pH} 7.5)$. Electrode impedances measured at $10 \mathrm{~Hz}$ ranged between 7 and $15 \mathrm{M} \Omega$. Filtered (AC, $0.3-10 \mathrm{kHz}$ ) and unfiltered (DC) electrode signals were amplified (P16; Grass Instruments) and fed to storage oscilloscopes (5110 and 5111; Tektronix, Beverton, OR), a thermal arraycorder (WR7600; Graphtek, Tokyo, Japan), and an audio monitor. Single-unit activity (signal-tonoise ratio of at least 3:1) was isolated with an amplitude spike discriminator (Centre d'Electronique et Microinformatique Institut National de la Santé et de la Recherche Medicale, Lyon, France) and collected on a personal computer via a Cambridge Electronic Design (Cambridge, UK) interface using the Spike 2 software, in parallel with analog-to-digital samplings of amplified (P55; Grass Instruments) polygraphic signals (EEG and EMG; sample rate, 100 or $200 \mathrm{~Hz}$ ). STN neurons were identified on-line by their stereotaxic location relative to bregma (Paxinos and Watson, 1996), i.e., anteroposterior, -3.6 to $-4.3 \mathrm{~mm}$; lateral, $2.0-3.0 \mathrm{~mm}$; and ventral, $7.5-8.3 \mathrm{~mm}$, as well as by their previously described extracellular biphasic spike waveform and their spontaneous activity dependent on the vigilance states. We have shown previously that STN neurons typically shift from a random discharge in W to a rhythmic bursty pattern in SWS without any change in their mean firing rate. In contrast, PS episodes were characterized by marked increases in the STN firing rate (Urbain et al., 2000).

Micropharmacology. To combine STN single-unit recordings with microiontophoresis, a seven-barrel micropipette (12-15 $\mu \mathrm{m}$ tip diameter) was glued alongside a recording electrode, as described previously (Akaoka et al., 1992). Four different barrels were filled with one of the following solutions: GABA (400 mM, $\mathrm{pH} 4$ ), bicuculline methiodide $\left(\mathrm{GABA}_{\mathrm{A}}\right.$ receptor antagonist, $\left.25 \mathrm{~mm}, \mathrm{pH} 4\right)$, gabazine $\left(\mathrm{GABA}_{\mathrm{A}}\right.$ antagonist, $5 \mathrm{~mm}, \mathrm{pH} 4)$, baclofen $\left(\mathrm{GABA}_{\mathrm{B}}\right.$ agonist, $\left.50 \mathrm{~mm}, \mathrm{pH} 4\right)$, and phaclofen $\left(\mathrm{GABA}_{\mathrm{B}}\right.$ antagonist, $50 \mathrm{~mm}, \mathrm{pH}$ 4). All drugs were purchased from Sigma (L'Isle d'Abeau Chesnes, France), except gabazine (SR95531; a gift from Sanofi Research, Montpellier, France), and were dissolved in distilled water. The remaining barrels, filled with $145 \mathrm{~mm}$ $\mathrm{NaCl}$, were used for automatic current balancing and current tests (Stone, 1985). To prevent drug diffusion, retaining currents (5-10 nA) were applied between periods of ejection. Analog signals proportional to the magnitudes of iontophoretic currents were collected on the computer via the Cambridge Electronic Design interface, in parallel to the singleunit and polygraphic recordings samplings.

Iontophoretic studies were typically conducted as follows. When a presumed STN unit was found, computer data collection was started, and a period of $\sim 5 \mathrm{~min}$ of spontaneous discharge was sampled before any drug application. When they had to be tested against their respective antagonists, short-duration iontophoretic pulses of GABA agonists were applied in a cyclic manner to induce regular and reproducible STN responses. Ejecting currents were chosen in such a way to induce a clear decrease in firing rate. Besides, prolonged low current GABA applications were invariably associated with a trend toward the total inhibition, leading to a nonstationary firing that avoided any correct quantitative analysis with the Poisson surprise method. Prolonged applications of GABA receptor antagonists led typically to a stable plateau of neuronal discharge allowing further quantitative pattern analyses. Iontophoretic currents were adapted to each individual cell, and high currents were generally avoided to limit the diffusional effect of the drug and to allow the recovery to the baseline activity. However, in several neurons, antagonist currents were progressively increased (up to $500 \mathrm{nA}$ ) to examine STN responses to higher amounts of drugs.

Histological verification of recording sites. On the fourth, third, and second days preceding the last recording session, iontophoretic deposits of pontamine sky blue (50\% duty, $20 \mathrm{sec}$ cycle for $30 \mathrm{~min},-30 \mu \mathrm{A})$ were made 1500,1000 , and $500 \mu \mathrm{m}$, respectively, above the STN to avoid possible electrolytic lesions of STN area for further recordings. On the last day of the experiment, the electrode was left in place at the final recording site, and a classical deposit of pontamine sky blue was performed $(-20 \mu \mathrm{A}$ for $10 \mathrm{~min})$. Then the animal was given a lethal dose of pentobarbital, and its brain was removed and immediately frozen in cold isopentane $\left(-20^{\circ} \mathrm{C}\right)$. Subsequent histological location of the four marked sites and electrode track reconstruction were made on $25-\mu \mathrm{m}$-thick cresyl violet-stained frontal sections.

Data analysis. The three classical vigilance states described in the rat were discriminated on the basis of the cortical EEG and neck EMG. W was identified by a low-amplitude and desynchronized EEG with sustained EMG activity. SWS was clearly distinguished by high-voltage delta waves $(0.5-5 \mathrm{~Hz})$ and spindles associated with weak EMG activity, the animal being immobile and its eyes closed. PS was characterized by a desynchronized EEG with a pronounced theta rhythm $(5.5-8.5 \mathrm{~Hz})$ and a complete loss of nuchal muscle tone. Basal and drug-induced firing rates and patterns were compared for periods matching for the same vigilance state using polygraphic criteria and EEG spectral analysis. Power spectra of the corresponding EEGs were calculated using the fast Fourier transform of the Spike 2 software.

Discharge rates of STN neurons were analyzed off-line for each vigilance state by the Spike 2 analysis software. Basal discharge rates of individual cells were typically determined for at least three separate 10 sec epochs in a given vigilance state out of any drug ejection or recovery period. Drug-induced effects were computed during plateau periods induced by iontophoretic pulses. The latency of a drug-induced effect was 
$\mathbf{A}$

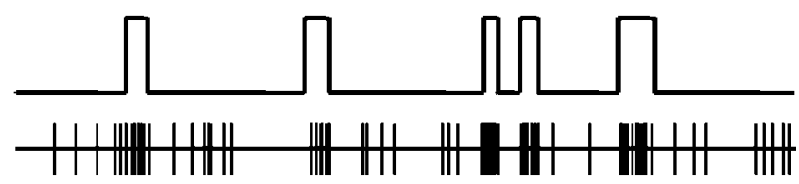

B

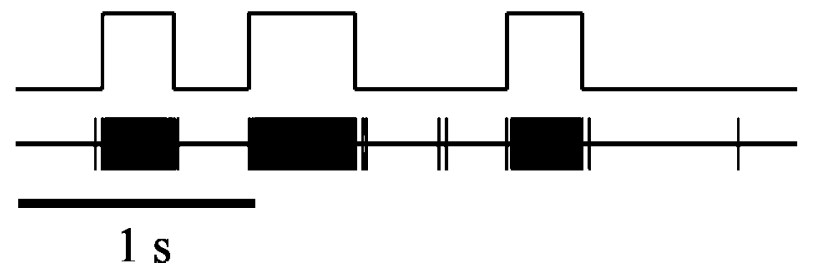

Figure 1. Burst detection method applied on a typical STN neuron recording during SWS, in the control condition $(A)$ and under a microiontophoretic application of a $\mathrm{GABA}_{\mathrm{A}}$ antagonist (bicuculline; $B$ ). This automatic detection was performed by a home-modified version of the surprise script provided by Cambridge Electronic Design in the Spike 2 software library (see Materials and Methods). Detected bursts from the corresponding single-unit activity are illustrated by square pulses on the top. As illustrated, such detection was reasonably satisfactory when applied both on a more or less bursty period recorded in spontaneous SWS $(A)$ and on a particularly identified bursty one during SWS under bicuculline $(B)$, without any downgrading of its overall performance.

defined as the interval between the onset of iontophoretic application of a drug and a firing rate deviation of at least $25 \%$ from baseline activity. Likewise, the recovery was the interval between the offset of the iontophoretic ejection and a stationary firing within $25 \%$ of the baseline.

For a given vigilance state, comparisons of basal and drug-induced firing rates of the same cells were performed using Student's $t$ tests for paired data. Comparisons of absolute firing rates computed in each vigilance state were performed using ANOVA with the vigilance state as a factor. Percent variations of drug-induced firing rates relative to baseline activity were compared with the nonparametric Wilcoxon signed ranks test for paired data, i.e., neurons recorded during at least two vigilance states, or with the nonparametric Kruskal-Wallis test for nonpaired data, e.g., comparisons between three vigilance states.

Discharge pattern of STN neurons, in correspondence with vigilance states, iontophoretic drug applications, or both, were analyzed off-line with a burst detection method that uses the Poisson surprise concept (Legendy and Salcman, 1985). Although the term "burst" is widely used, there has been no strict definition given: bursts are commonly viewed as a period in a spike train that has a much higher discharge rate than surrounding periods in the spike train (Kaneoke and Vitek, 1996), and no general method of detection has been developed. Given the marked disparity between SWS spontaneous bursts (more or less discernible individually) and particularly clear-cut bursts under $\mathrm{GABA}_{\mathrm{A}}$ antagonists application, the surprise method appeared well adapted to our data. However some changes in the "surprise script" for the Cambridge Electronic Design Spike 2 software were required to detect with reasonable performance both types of bursts with the same algorithm to make appropriate statistical comparisons between treatments. We added to the original script a moving $10 \mathrm{sec}$ windowing of raw data and settled the burst termination when 6 consecutive spikes failed to improve the calculated surprise or as soon as an interval twice the mean interspike interval was encountered (Legendy and Salcman, 1985). This greatly improved burst detection in our STN recordings. Figure 1 illustrates the overall satisfactory performance of this home-modified version of the original algorithm, both for spontaneous and drug-induced bursts. This algorithm provided, over a given period and for each neuron analyzed, the number of bursts, the mean number of spikes per burst, the mean burst duration, the mean interval between the beginnings of each burst (i.e., the periodicity of bursts, in seconds), and the mean frequency within bursts.

For all statistical analyses of firing rates and discharge patterns, the significance level was set at $p<0.05$. All data are expressed as mean \pm SEM.

\section{RESULTS}

One hundred seven neurons showing discharge properties characteristic of STN neurons were recorded during different vigilance states in 14 rats. In this database, 97 were recorded both in SWS and W, 32 through an SWS to PS or a PS to SWS transition, and 30 during a PS to $\mathrm{W}$ transition. These cells were identified as presumed STN neurons on the basis of the short $(\sim 1 \mathrm{msec}$ duration) and biphasic waveform of their extracellular spikes as well as the particular spontaneous activity across the sleep-wake cycle that we described recently (Urbain et al., 2000); they shifted invariably from a random discharge in $\mathrm{W}$ to a rhythmic bursty pattern in SWS without any significant change in their mean firing rate $(\mathrm{W}, 14.7 \pm 0.9$ spikes $/ \mathrm{sec} ; n=100 ;$ vs SWS, $16.9 \pm 1.0$ spikes/sec; $n=102$ ). In addition, 33 of these neurons were also recorded during a PS episode, during which they doubled their mean firing rate $(35.5 \pm 2.7$ spikes/sec) relative to SWS and W $(p<0.001$; ANOVA). The location in the STN of all these neurons was supported by subsequent histological verifications.

Given the fact that, on this anesthetic-free preparation, animals exhibited spontaneous alternating of the three vigilance states without forewarning the experimenter, and whatever the iontophoretic protocol used, it was not always possible to sample both the baseline and the drug-induced firing of a neuron during the same vigilance state. Consequently, only paired data obtained during a given vigilance state on a given cell, both in control conditions and during drug applications, have been considered below for appropriate statistical analyses.

\section{Response of STN neurons to GABA agonists}

Iontophoretic applications of GABA were performed on 34 STN neurons during W, SWS, or PS. As illustrated in Figure 2, ejections of GABA ( $68 \pm 7 \mathrm{nA}$ for $8 \pm 1 \mathrm{~s})$ led to a fast (typically $1-3$ $\mathrm{s}$ range) and marked dose-dependent decrease of the STN firing rate whatever the vigilance state $(\mathrm{W},-68.2 \pm 4.5 \% ; p<0.001$; $n=20$; SWS, $-75.5 \pm 3.1 \% ; p<0.001 ; n=28$; PS, $-66.8 \pm$ $11.8 \% ; p<0.01 ; n=8)$. Recovery to baseline activity took only a few seconds. This depression of the firing rate under GABA was not statistically different among the three vigilance states $(p=$ 0.48; ANOVA). In all tested cells, these GABA-induced inhibitions were antagonized by co-iontophoresis of the $\mathrm{GABA}_{\mathrm{A}}$ antagonists bicuculline $(61 \pm 9 \mathrm{nA} ; n=10)$ (Fig. $2 A)$ and gabazine $(107 \pm 25 \mathrm{nA} ; n=3)$ (Fig. 2B). Occasionally, we observed transient increases in the firing rate during $\mathrm{W}$, which were timelocked with brisk movements of the animal despite the potent iontophoretic GABA-induced inhibitions on which they were superimposed.

To examine the effect of GABA on the STN firing pattern, we also used moderate and prolonged GABA applications that induced only slight inhibitions (to be sure that GABA was going out of the pipette), although trends toward total inhibitions were obtained with sufficient amounts of GABA. As illustrated in Figure 3, STN neurons, that exhibited a bursty pattern in SWS, kept this bursty pattern during clear GABA-induced inhibitions. Likewise, if applied in W, when STN neurons showed a random discharge, GABA did not alter this pattern. Furthermore, a rebound burst-like pattern was never observed after the end of GABA applications.

Effects of iontophoretic applications of the specific $\mathrm{GABA}_{\mathrm{B}}$ receptor agonist baclofen were examined on 28 neurons. Baclofen $(113 \pm 6 \mathrm{nA}$ for $10 \pm 1 \mathrm{~s})$ typically induced a progressive and long-lasting decrease of the STN firing rate (Fig. 4; W, $-61.5 \pm$ $6.6 \% ; p<0,001 ; n=19$; SWS, $-63.5 \pm 5.2 \% ; p<0.001 ; n=18$; 
A

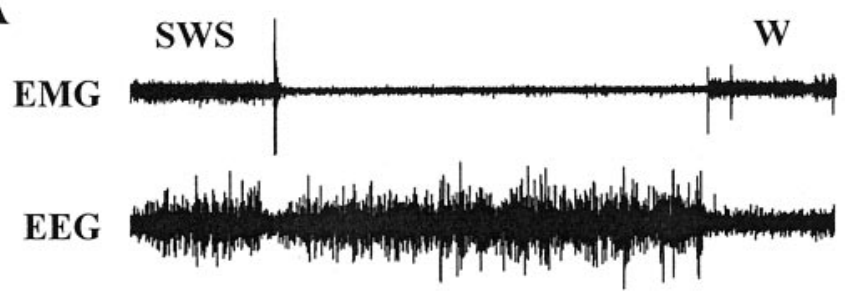

Bicuculline (100 nA)

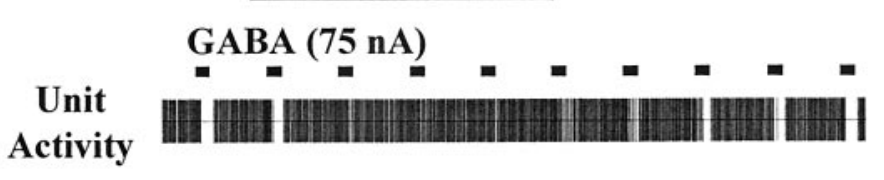

B

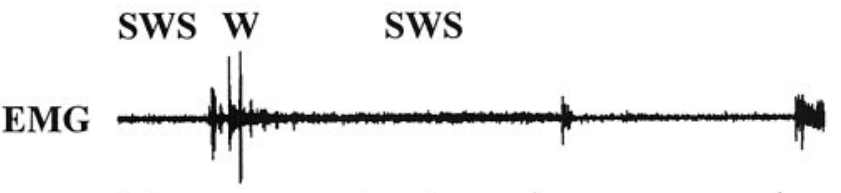

EEG

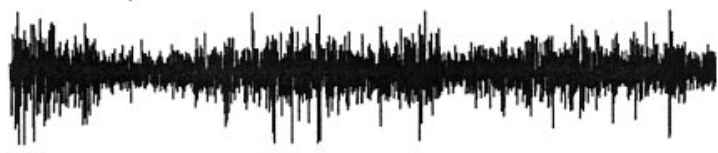

GBZ (200 nA)

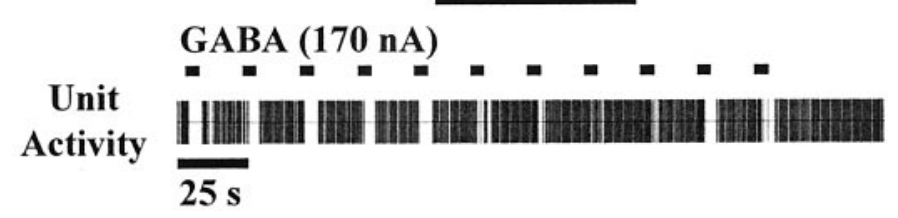

Figure 2. Typical inhibitions of STN neurons induced by iontophoretic applications of GABA along the spontaneous alternance of SWS and W and their blockade by the co-iontophoretic ejection of the $\mathrm{GABA}_{\mathrm{A}}$ antagonists bicuculline $(A)$ and gabazine $(B)$. In each panel, below the polygraphic recordings (EMG and EEG), the horizontal black lines indicate ejection pulses for each compound with corresponding iontophoretic currents. The bottom part relates to the corresponding single-unit activity.

PS, $-21.5 \pm 18.8 \% ; p=0.27 ; n=5)$. This response started a few seconds after the beginning of baclofen applications $(7 \pm 1 \mathrm{~s} ; n=$ 28 ). However, in contrast with GABA-induced inhibition, it developed slowly, and the recovery time was relatively longer (36 \pm $10 \mathrm{sec} ; n=23)$. In addition, only a few total inhibitions were obtained ( 5 of 23). As observed with GABA, the firing pattern of STN neurons across the sleep-wake cycle was not qualitatively altered by baclofen applications; i.e., STN neurons exhibited a bursty pattern in SWS and a more or less regular one in W. In all tested neurons $(n=16)$, co-iontophoresis of the $\mathrm{GABA}_{\mathrm{B}}$ antagonist phaclofen antagonized the baclofen-induced inhibitions (Fig. 4) but not the $\mathrm{GABA}_{\mathrm{A}}$-induced ones.

\section{Response of STN neurons to GABA antagonists}

Whatever the vigilance state, iontophoretic applications of the $\mathrm{GABA}_{\mathrm{A}}$ antagonists bicuculline (61 $\pm 9 \mathrm{nA}$ for $125 \pm 43 \mathrm{sec} ; n=$ $36)$ on gabazine $(107 \pm 25 \mathrm{nA}$ for $114 \pm 47 \mathrm{sec} ; n=9)$ induced a progressive and sustained increase of the firing rate of all neurons recorded in the STN. The latency of this effect was $\sim 9$ sec, and firing rate was almost doubled across the first minute of bicuculline or gabazine ejection (Fig. $5 A$ ). If application was
$\mathbf{A}$
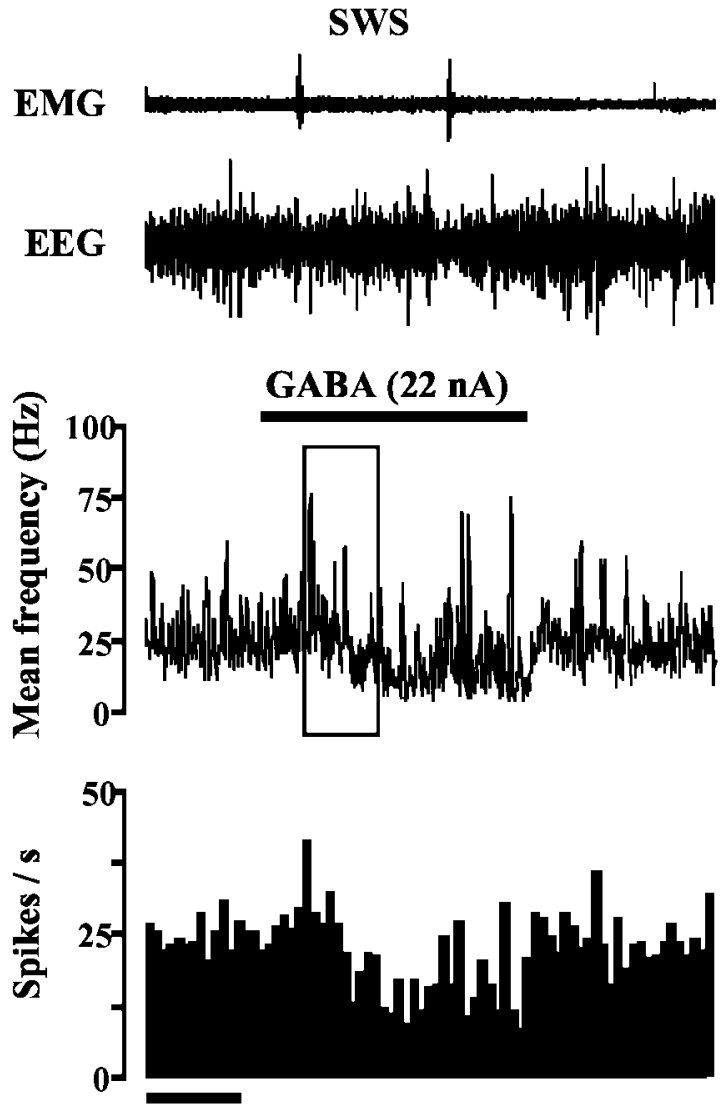

$25 \mathrm{~s}$

B

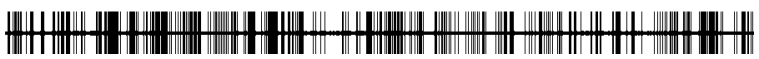

Figure 3. Illustration of the inability of iontophoretic GABA applications to clearly alter the spontaneous occurrence of a bursty pattern in STN neurons during a SWS episode. $A$, Below the $E M G$ and $E E G$ raw traces, the firing pattern of an STN neuron is summarized on a large time scale by plotting the mean instantaneous frequency (in hertz, mean of the inverse of intervals between events, computed at each event over a $0.5 \mathrm{sec}$ period) versus time. Large variations of this index are indeed more indicative of marked nonstationary conditions (e.g., during bursting activity) than the classical discharge rate histogram (event counts over $2 \mathrm{sec}$ periods, expressed in spikes per second) displayed immediately below. Although this GABA application induces a progressive decrease in the mean firing rate up to $50 \%$, it is ineffective to dampen the variability in instantaneous frequencies. Note also that some transient increases in instantaneous frequencies were rather attributable to spontaneous microawakenings (see $E M G$ trace). $B$, Single-unit activity on an expanded time scale; the length of the recording corresponds to the width of the boxed area in $A$. Note the persisting bursty pattern of this STN neuron as its mean firing rate starts to decrease.

stopped, the recovery to baseline took typically several tens of seconds; otherwise, the neuronal mean firing rate increased progressively to a plateau whose level depended on the recorded cell and the current applied.

In addition, we evaluated maximal firing abilities of STN neurons. On five STN neurons, particularly high currents (up to 500 $\mathrm{nA}$ and $100 \mathrm{sec}$ ) of bicuculline were progressively applied to follow the STN neuron response to the highest doses. Although the mean firing rate of three of these five cells was slightly increased by such high currents, the mean firing rate of the two other cells was not further enhanced. Likewise, the firing pattern as well as the modifications of the discharge rate related to 

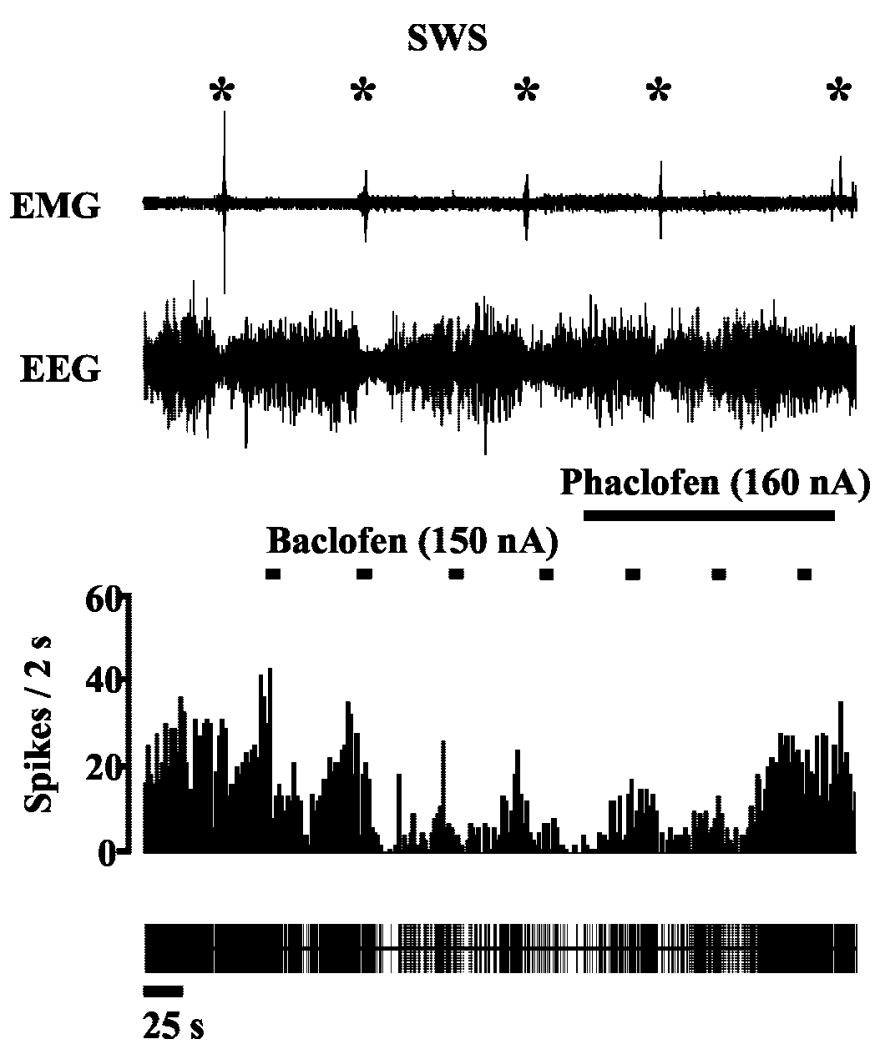

Figure 4. Example of baclofen-induced inhibitions and their blockade by co-iontophoresis of the $\mathrm{GABA}_{\mathrm{B}}$ antagonist phaclofen. This STN neuron was recorded during an SWS period interrupted by short periods of $\mathrm{W}$ (microarousals indicated by stars). In each panel, below the polygraphic recordings ( $E M G, E E G)$, the horizontal black lines indicate ejection pulses for each compound with corresponding iontophoretic currents. The bottom part relates to the rate histogram (spike counts with a $2 \mathrm{sec}$ bin width) and the corresponding single-unit activity of this STN neuron.

vigilance states were not further affected by high doses of bicuculline compared with the lower ones; i.e., STN neurons shifted typically from a bursty pattern in SWS to a more regular one in W (see below). Moreover, no sign of depolarization blockade was observed at the highest currents tested. Because increases of the firing rate induced by high currents of bicuculline were similar to those induced by lower ones, all data were pooled for this particular evaluation. Overall, STN activity was significantly enhanced by bicuculline application up to three to five times its basal activity, and maximal STN mean firing rates (computed as the highest mean firing rate in $20 \mathrm{sec}$ periods) were quite similar between the three vigilance states ( $p=0.45$; ANOVA; W, $92.2 \pm$ 12.5 spikes/sec; range, 31.8-184.3; SWS, $103.0 \pm 10.6$ spikes/sec; range, 26.8-184.1; PS, $124.1 \pm 20.1$ spikes/sec; range, 59.0-177.8).

Furthermore, dramatic alterations of the firing pattern were related to changes in the firing rate. When $\mathrm{GABA}_{\mathrm{A}}$ antagonist applications began during SWS episodes, a particularly robust bursty pattern developed in the majority of STN cells (Fig. 5B). Salient bursts started to occur several tens of seconds after the beginning of bicuculline $(28 \pm 4 \mathrm{sec} ; n=18)$ or gabazine $(25 \pm$ $6 \mathrm{sec} ; n=5$ ) applications. Burst analysis of the corresponding subsets of SWS-paired data for bicuculline and gabazine is summarized in Table 1. In contrast, when antagonist applications began during $\mathrm{W}$ episodes, such strong bursts only rarely occurred, but as soon as the rat fell asleep, they typically started to develop.

During SWS, bicuculline or gabazine increased the frequency of occurrence of bursts and their duration, as well as the number of spikes per bursts (Table 1). Such bursts were markedly different from the spontaneous ones observed during SWS. This derived mainly from the sustained high frequencies of spikes noticeable within each burst (Fig. 6), thus delineating clearly isolated bursts. With both antagonists, almost all bursts started with few consecutive spikes speeding up to reach a brief episode of instantaneous frequencies typically as high as $500-600 \mathrm{~Hz}$, followed by a long series of spikes slowing down toward the end of each burst (Fig. 7). Such high mean or instantaneous frequencies within bursts were only rarely observed within control bursts appearing spontaneously during SWS episodes (Table 1, Fig. 6), which were also never so sustained for a long time.

This property of $\mathrm{GABA}_{\mathrm{A}}$ antagonists to induce such a robust bursty pattern almost exclusively during SWS was largely confirmed on STN neurons recorded during both an ongoing antagonist application and a spontaneous SWS-W transition $(n=17)$ or an SWS-PS one $(n=5)$. Strikingly, these marked SWS bursts typically disappeared when rats woke up (Fig. 5) or were strongly modified during PS episodes (Fig. 8). As illustrated in Figure 5B, although bicuculline was still applied with the same iontophoretic parameters, the awakenings of the rat were typically associated with an immediate regularization of the bursty pattern. In addition, this shift in the STN discharge was associated with a significant decrease of the enhanced mean firing rate under bicuculline (from $+277.0 \pm 51.2 \%$ in SWS to $+161.0 \pm 49.7 \%$ in W; Wilcoxon test between SWS and $\mathrm{W}, p<0.05)$. The same was observed for gabazine (Fig. $5 C$ ). In contrast, when spontaneous SWS-PS transitions occurred under bicuculline, the STN neuron firing rate was nonsignificantly affected (SWS, $113.2 \pm 18.5$ spikes/sec; vs PS, $134.8 \pm 14.4$ spikes/sec). Actually, strong PS bursts, similar to those observed in SWS, were still recorded during bicuculline or gabazine applications, but whereas they were isolated bursts occurring on a silent background in SWS (Fig. 8, SWS), numerous single spikes randomly appeared between more or less clear bursts in PS (Fig. 8, PS).

In contrast to the $\mathrm{GABA}_{\mathrm{A}}$ receptor antagonists, the specific $\mathrm{GABA}_{\mathrm{B}}$ receptor antagonist phaclofen did not have marked or consistent effects on the STN discharge activity. Iontophoretic applications of phaclofen $(185 \pm 7 \mathrm{nA}$ for $157 \pm 55 \mathrm{sec})$ during W and SWS were performed on 10 STN neurons. Neither the STN mean firing pattern nor the firing rate was significantly altered by phaclofen applications during $\mathrm{W}$ or $\mathrm{SWS}(\mathrm{W},+13.9 \pm 17.2 \%$; $n=$ 7 ; SWS, $+5.3 \pm 12.0 \% ; n=9$ ).

\section{DISCUSSION}

To our knowledge, the present work is the first to describe the effects of iontophoretic applications of GABA agonists and antagonists on STN neurons in the rat free of any interference with anesthetic or immobilizing drugs. In agreement with studies that have described $\mathrm{GABA}_{\mathrm{A}}$ and $\mathrm{GABA}_{\mathrm{B}}$ receptors in the STN (Zhang et al., 1991; Wisden et al., 1992; Charara et al., 2000; Schwarzer et al., 2001), iontophoretic applications of GABA or the $\mathrm{GABA}_{\mathrm{B}}$ agonist baclofen decreased the STN firing rate, effects blocked by the selective antagonists bicuculline (or gabazine) and phaclofen, respectively. Bicuculline or gabazine alone altered STN activity whatever the vigilance state, contrary to the $\mathrm{GABA}_{\mathrm{B}}$ receptor antagonist phaclofen, which had no effect. This suggests that STN cells are under a tonic GABAergic tone across the entire sleep-wake cycle, predominantly mediated via $\mathrm{GABA}_{\mathrm{A}}$ receptors. We found also that applications of $\mathrm{GABA}_{\mathrm{A}}$ antagonists promoted a robust bursty pattern selectively during 

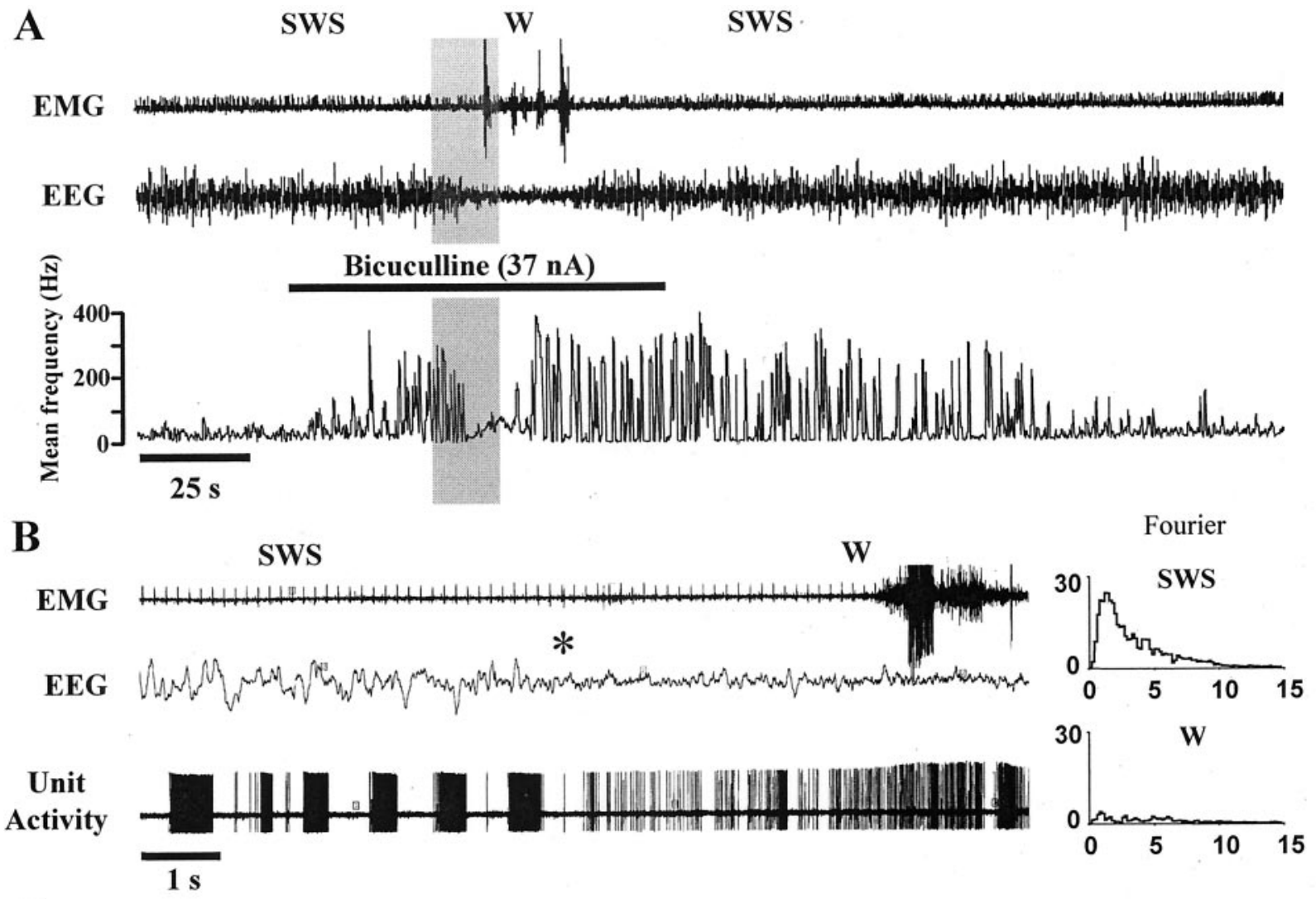

C

SWS

W
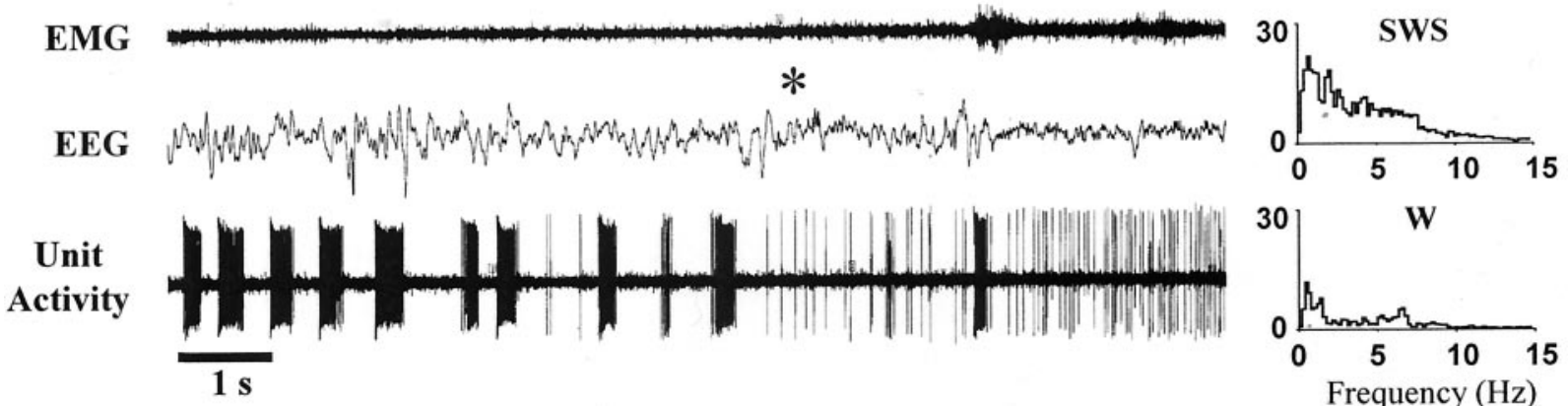

Frequency $(\mathrm{Hz})$

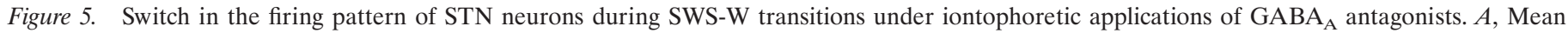
instantaneous frequency (in hertz, computed at each event in $0.5 \mathrm{sec}$ ) versus time of an STN neuron before, during, and after the iontophoretic ejection of bicuculline (black horizontal bar) together with the corresponding polygraphic recordings (EMG, EEG, top). Note the progressive increase in frequency leading to a well established SWS bursty pattern $\sim 30 \mathrm{sec}$ after the onset of bicuculline application. Note also its dramatic decrease associated with the spontaneous appearance of a short $\mathrm{W}$ episode, as well as the progressive reappearance of a bursty pattern during the consecutive transient drowsiness period, which fully comes back during reinstallation of typical SWS. The total recovery to baseline activity in SWS took $\sim 3$ min after the offset of bicuculline application. $B$, Raw traces of polygraphic recordings and single-unit activity during the SWS-W transition of the STN neuron shown in $A$ but with an expanded time scale corresponding to the shaded area in $A$. Superimposed deflections on the EMG trace correspond to the electrocardiogram of this animal, which can sometimes be recorded during particularly low muscular tone SWS episodes. The frequency spectra (relative power in the $0-15$ $\mathrm{Hz}$ band, computed over $10 \mathrm{sec}$ before and after the change in vigilance state indicated by a star) of the corresponding EEGs are shown on the right. They typically illustrate the high-voltage slow waves in the delta range $(0.5-5 \mathrm{~Hz})$ observed in SWS and the low-amplitude and desynchronized EEG in W. On the single-unit trace, spikes were unfortunately truncated in their negative part because of the settings of the Graphtek thermal printer. Note in particular that bicuculline-induced marked bursts in SWS suddenly vanished when the rat spontaneously woke up. Note also the increased discharge activity associated with brisk movements in quiet W (see EMG trace). $C$, Same representation as in $B$ of another STN neuron during an SWS-W transition occurring during the ongoing iontophoresis of another $\mathrm{GABA}_{\mathrm{A}}$ antagonist, gabazine.

SWS, pointing out the critical but not exclusive role of GABA in STN firing pattern regulation.

The STN receives mainly GABAergic afferents from the GP (Albin et al., 1989; DeLong, 1990). The GP projection is massive (Van der Kooy and Kolb, 1985; Moriizumi and Hattori, 1992), distributed to the whole extent of the STN (Kitai and Kita, 1987;
Canteras et al., 1990; Smith et al., 1990), and there is evidence that GP cells may inhibit STN neurons (Rouzaire-Dubois et al., 1980; Kita et al., 1983; Smith et al., 1990). It is known that most GP neurons are GABAergic (Smith et al., 1990; Kita, 1994; Bell et al., 1995). Moreover, the synaptic organization of the GP terminals in STN suggests that the GP exerts a powerful 
Table 1. Quantitative parameters of the SWS burst-firing mode

\begin{tabular}{|c|c|c|c|c|}
\hline & \multicolumn{2}{|l|}{ A } & \multicolumn{2}{|l|}{$\mathrm{B}$} \\
\hline & Control & Bicuculline & Control & Gabazine \\
\hline Number of spikes/burst & $11.8 \pm 0.7$ & $102.0 \pm 13.0^{*}$ & $12.3 \pm 1.0$ & $43.1 \pm 4.2^{* *}$ \\
\hline Bursts duration (msec) & $143.3 \pm 8.7$ & $309.9 \pm 31.6^{*}$ & $130.2 \pm 25.0$ & $169.0 \pm 6.1$ \\
\hline Interval between burst onsets (sec) & $1.6 \pm 0.2$ & $1.2 \pm 0.1^{* * *}$ & $1.3 \pm 0.2$ & $1.0 \pm 0.2$ \\
\hline Mean frequency within bursts (spikes/sec) & $105.8 \pm 6.5$ & $295.4 \pm 15.1^{*}$ & $128.5 \pm 16.0$ & $244.8 \pm 28.4^{* *}$ \\
\hline
\end{tabular}

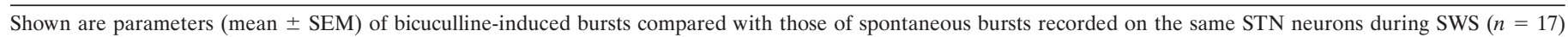

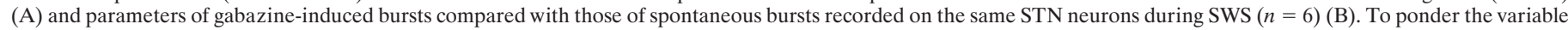

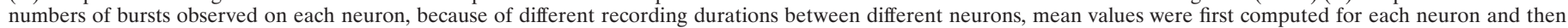

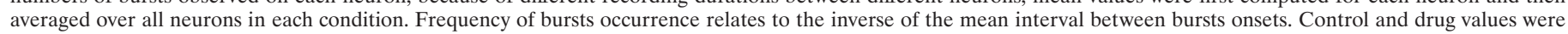
compared with the Student's $t$ test for paired data.

${ }^{*} p<0.001$.

$* * p<0.01$.

$* * * p<0.05$.
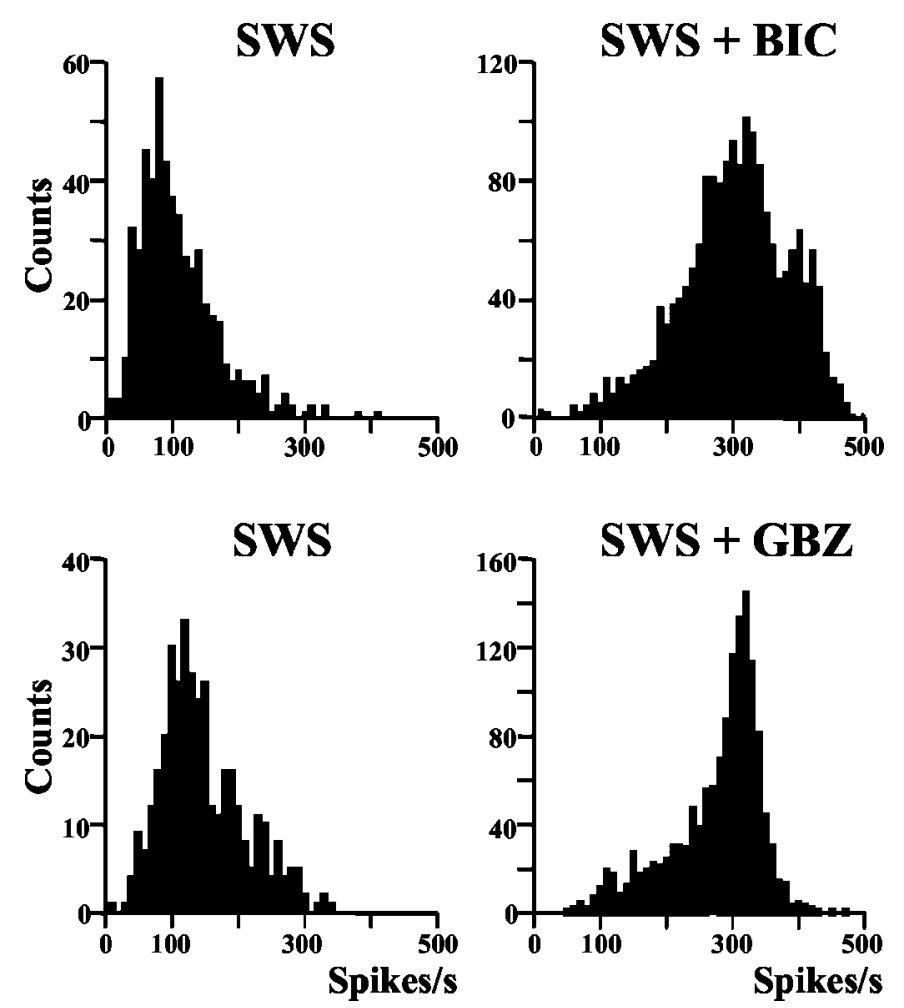

Figure 6. Histograms of the mean frequencies within all bursts of 2 groups of STN neurons ( $n=17$, top; $n=6$, bottom) recorded both in control SWS (left column; 526 and 369 bursts, respectively) and during iontophoresis of the GABA antagonists in SWS (right column; bicuculline, $S W S+B I C, 1767$ bursts; gabazine, $S W S+G B Z, 1359$ bursts). Note that, for both groups, mean frequencies within bursts were distributed at $\sim 100 \mathrm{~Hz}$ in typical SWS, whereas they were significantly increased during the same vigilance state to $\sim 300 \mathrm{~Hz}$ by both $\mathrm{GABA}_{\mathrm{A}}$ antagonists. Note also the shoulder on the right of the SWS + BIC histogram reflecting the somewhat higher frequencies within bicuculline-induced bursts compared with the gabazine-induced ones.

GABAergic control over the STN (Van der Kooy et al., 1981; Smith et al., 1990; Bevan et al., 1997).

Consequently, and as expected, we found that local GABAergic agonists were potent inhibitors of STN neurons and that $\mathrm{GABA}_{\mathrm{A}}$ antagonists easily induced their disinhibition, as described previously in the anesthetized rat (Rouzaire-Dubois et al., 1980; Féger et al., 1991). At first glance, the $\mathrm{GABA}_{\mathrm{A}}$ antagonist-induced bursty pattern that we selectively observed in
SWS does agree with our previous data (Urbain et al., 2000), according to which STN spontaneous bursts developing when the rat fell asleep were associated with a reduction in the GABAergic GP tone. It also agrees with the STN rebound burst firing observed in vitro after removal of hyperpolarization (Nakanishi et al., 1987; Overton and Greenfield, 1995; Beurrier et al., 1999; Bevan et al., 2000), although we never observed such a phenomenon after the offset of GABA applications. The lack of effect of GABA to affect the STN random pattern in W may seem at variance with the tonic-bursting switch in discharge induced by hyperpolarization in vitro (Beurrier et al., 1999), but we cannot exclude a preponderant membrane shunting effect by iontophoretic $\mathrm{GABA}_{\mathrm{A}}$ receptor activation (Baufreton et al., 2001).

One of the most striking results of the present study is that $\mathrm{GABA}_{\mathrm{A}}$ antagonists selectively reinforced the spontaneous SWS bursty pattern, leading to well delineated long bursts with intraburst instantaneous frequencies as high as 500-600 Hz, only rarely observed in baseline conditions. Such bursts are likely related to $\mathrm{GABA}_{\mathrm{A}}$ receptor blockade, because they were evoked by both the $\mathrm{GABA}_{\mathrm{A}}$ antagonists bicuculline and gabazine (SR-95531; Heaulme et al., 1986; Michaud et al., 1986; Mienville and Vicini, 1987; Hamann et al., 1988; Yu and Ho, 1990; Rognan et al., 1992; Mestdagh and Wulfert, 1999). The additional bicuculline-induced blockade of calcium-activated potassium currents (Johnson and Seutin, 1997; Seutin et al., 1997; Debarbieux et al., 1998; Khawaled et al., 1999; Mestdagh and Wulfert, 1999) or inhibition of acetylcholinesterase activity (Svenneby and Roberts, 1973; Miller and McLennan, 1974) might explain the somewhat longer burst duration evoked by this compound compared with gabazine (Table 1).

It must also be emphasized that this typical SWS bursty pattern emerged several tens of seconds after the onset of antagonist applications. This delay might be linked to the requirement of the blockade of postsynaptic $\mathrm{GABA}_{\mathrm{A}}$ receptors localized on distal dendrites. However, we cannot exclude the involvement of other complex interactions between particular STN intrinsic membrane properties (Beurrier et al., 1999; Bevan et al., 2000) and presynaptic mechanisms through various inputs distributed along the STN dendritic field, involving, for example, glutamatergic afferents that make synaptic contacts preferentially on distal dendrites (Bevan et al., 1995). More surprisingly, although $\mathrm{GABA}_{\mathrm{A}}$ receptors were still blocked by ongoing $\mathrm{GABA}_{\mathrm{A}}$ antagonist applications, STN neurons suddenly switched, as soon as rats woke up, from a robust high-frequency bursting pattern to a regular one. The intrinsic GABAergic tone appears then 


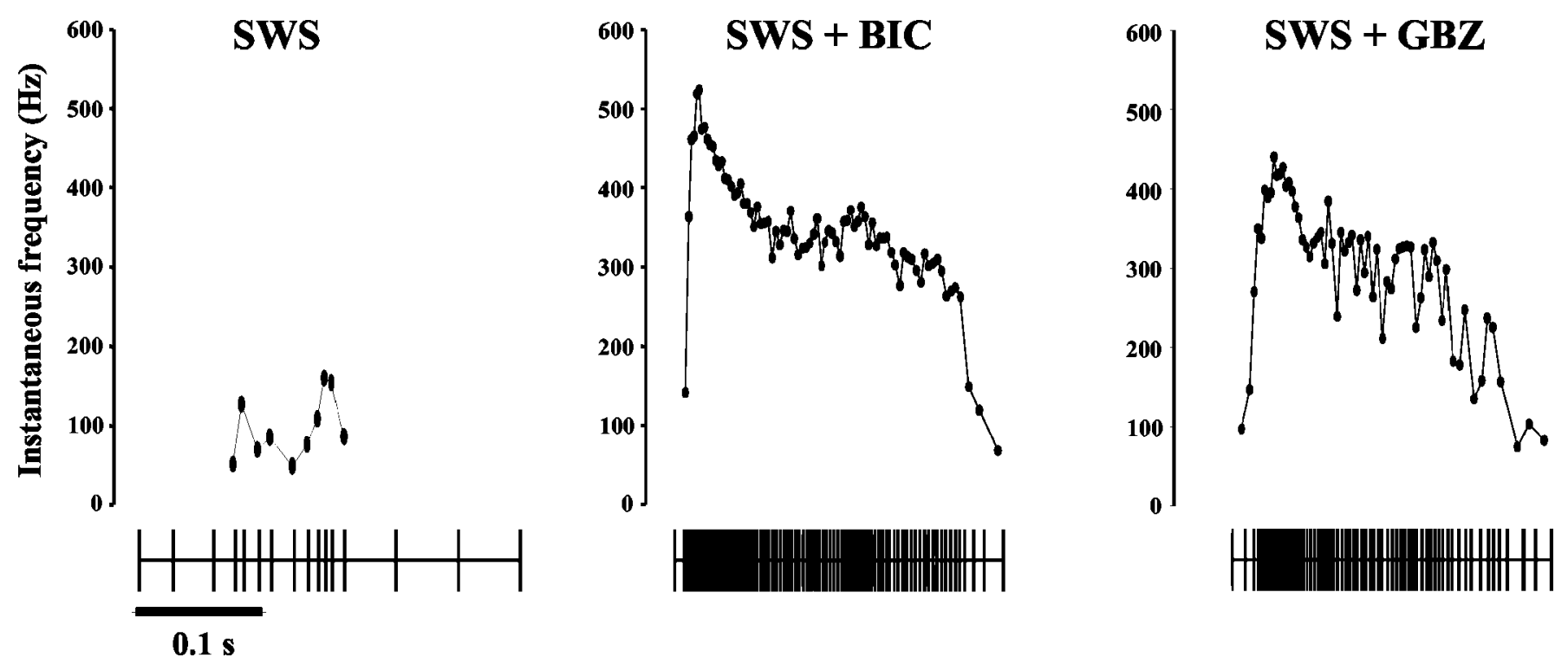

Figure 7. Representation of the instantaneous frequencies computed for each consecutive interval making up typical bursts of STN neurons. Bursts were automatically detected by the Poisson surprise method during SWS episodes in a control condition (SWS) and under iontophoretic application of bicuculline $(S W S+B I C)$ or gabazine $(S W S+G B Z)$. Plot resolution does not permit discrimination of particularly timely close spikes.

to be overridden by another phenomenon that regularizes STN discharge in wakefulness.

In addition, clear disinhibitions or changes of firing pattern were not induced by $\mathrm{GABA}_{\mathrm{B}}$ antagonist iontophoresis. This might be attributable to the recent description, in STN, of $\mathrm{GABA}_{\mathrm{B}}$ receptors not only on postsynaptic targets but also on glutamatergic and GABAergic terminals. It must be underlined that most of these anatomical studies have been performed on monkeys, with only two studies in abstract form on the rat (Booth et al., 2000; $\mathrm{Ng}$ and Yung, 2001). The lack of effects of $\mathrm{GABA}_{\mathrm{B}}$ antagonist applications might come from the result of a presynaptic blockade of $\mathrm{GABA}_{\mathrm{B}}$-induced inhibition of glutamate but also GABA release, as suggested by Shen and Johnson (2001).

In summary, it appears that, if the blockade of $\mathrm{GABA}_{\mathrm{A}}$ receptors within STN favors the emergence of a particularly robust bursty pattern, it is, however, not sufficient. These data also rule out that the regularization of STN spontaneous activity in W might result solely from the related increase in the GP firing rate, as we have suggested recently (Urbain et al., 2000). Therefore, the switch of STN neurons between a tonic regular and bursty pattern likely involves other afferents than those of the simplified GP-STN network proposed in vitro by Plenz and Kitai (1999), and mechanisms other than the strong inhibitory input from the GP are likely able to shape the activity of STN cells (Mink and Thach, 1993; Albin et al., 1995; Hassani et al., 1996; Kreiss et al., 1996, 1997; Nakao et al., 1998; Magill et al., 2000).

Actually, during SWS, thalamic and cortical cells oscillate in a low-frequency range (Steriade, 1993; Steriade et al., 1993; Contreras and Steriade, 1997a,b; McCormick and Bal, 1997). Because projections from the cortex and parafascicular nucleus of the thalamus to STN cells are well documented (Kitai and Deniau, 1981; Afsharpour, 1985; Kitai and Kita, 1987; Fujimoto and Kita, 1993; Mouroux and Féger, 1993; Féger et al., 1994; Bevan et al., 1995; Mouroux et al., 1995, 1997), and because STN neurons are extremely sensitive to small changes in their excitatory inputs (Kitai and Kita, 1987; Bevan and Wilson, 1999), such afferents are therefore in a position to efficiently shape the STN activity (Magill et al., 2000, 2001). Other mechanisms and afferents are also potentially in a position to modulate the STN neuronal activity, in particular, those linked to mesopontine and raphe nuclei inputs, both involved in sleep-wake mechanisms (Hammond et al., 1983; Canteras et al., 1990; Bevan and Bolam, 1995).

Reduction of tonic pallidal inhibition, as it may result from a dopamine depletion in PD (DeLong, 1990), should have a profound effect by disinhibiting the STN. Indeed, a rhythmic bursting activity of STN neurons, phase-related to a resting tremor, has been evidenced in idiopathic and animal models of PD (Bergman et al., 1994, 1998; Wichmann et al., 1994b; Rodriguez et al., 1998; Levy et al., 2000; Magariñoz-Ascone et al., 2000). We found that STN disinhibition by local $\mathrm{GABA}_{\mathrm{A}}$ antagonists resulted in the emergence of robust burst discharges, as observed previously in the anesthetized rat (Féger et al., 1991). Moreover, GP lesions have been shown to increase the degree of coordination of STN neuron activity and to enhance the neuronal response to motor cortex stimulation (Ryan and Clark, 1992; Ryan et al., 1992), and this may be related to our observation that, in SWS and during $\mathrm{GABA}_{\mathrm{A}}$ antagonist applications, we could sometimes hear surrounding STN neurons firing in synchronized bursts. These data suggest that GABA afferents might act as a gating mechanism for the STN firing pattern, and blockade of such afferents could decrease the selectivity of cortical control of the STN but increase STN responsiveness, thus leading to inappropriate motor behavior.

Clinical observations showed that most PD symptoms are alleviated by STN high-frequency stimulation (Benazzouz et al., 1993; Benabid et al., 1994; Limousin et al., 1995a,b). Nowadays, the preponderant hypothesis is that such stimulation might act through the depolarization blockade of STN cell bodies (Burbaud et al., 1994; Benazzouz et al., 1995, 2000). However, as observed previously in vitro (Nakanishi et al., 1987; Bevan and Wilson, 1999; Wigmore and Lacey, 2000), we found that disinhibited STN neurons were able to fire in vivo at very high frequencies, up to 175-185 spikes/sec for mean frequencies and up to $600 \mathrm{spikes} / \mathrm{sec}$ for instantaneous frequencies. In addition, as reported previously in the awake primate (Wichmann et al., 1994b), we never observed depolarization blockade of STN neurons even under the highest amounts of bicuculline tested, in contrast with anesthe- 


\section{A: Under bicuculline}

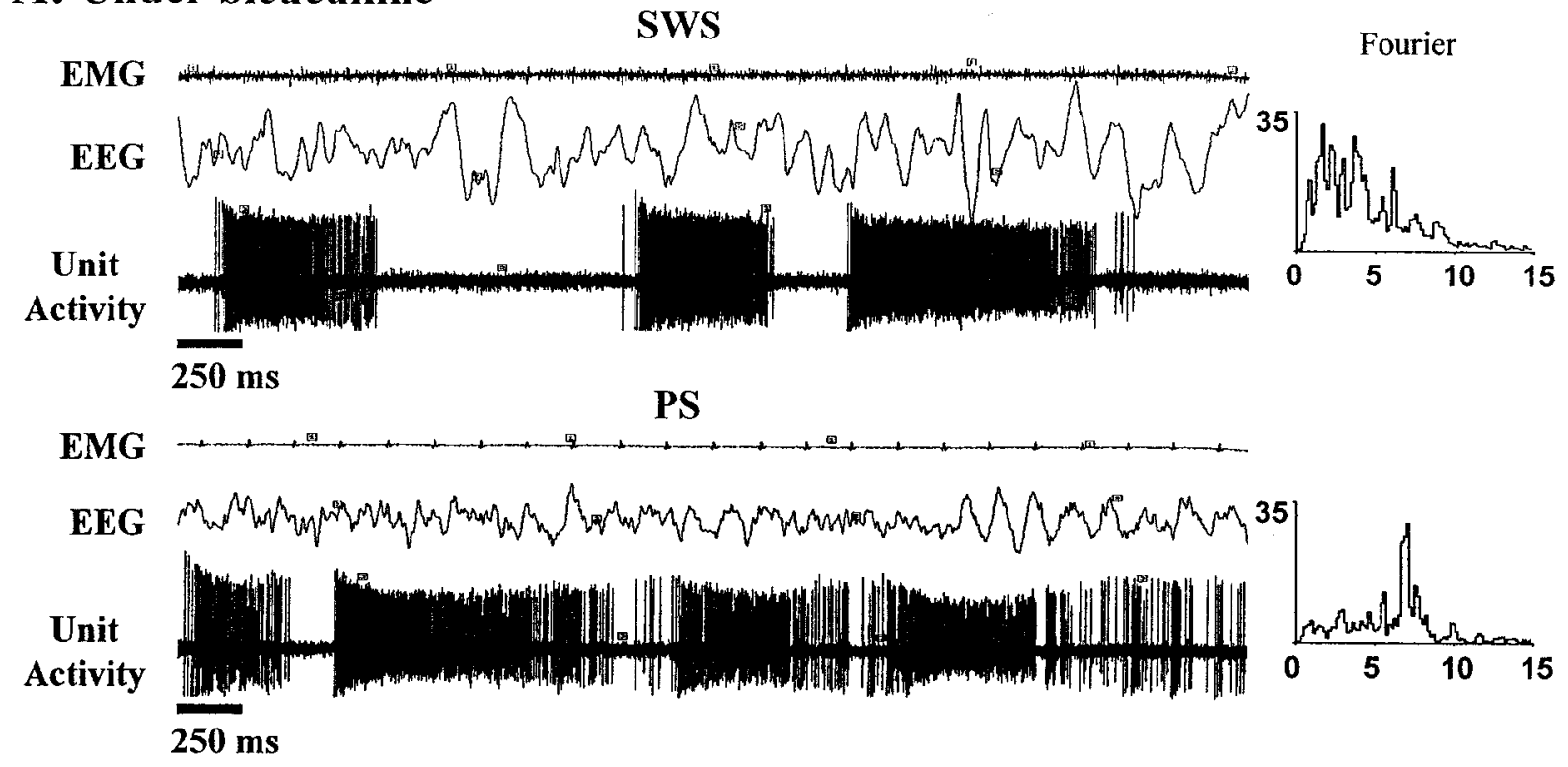

\section{B: Under gabazine}

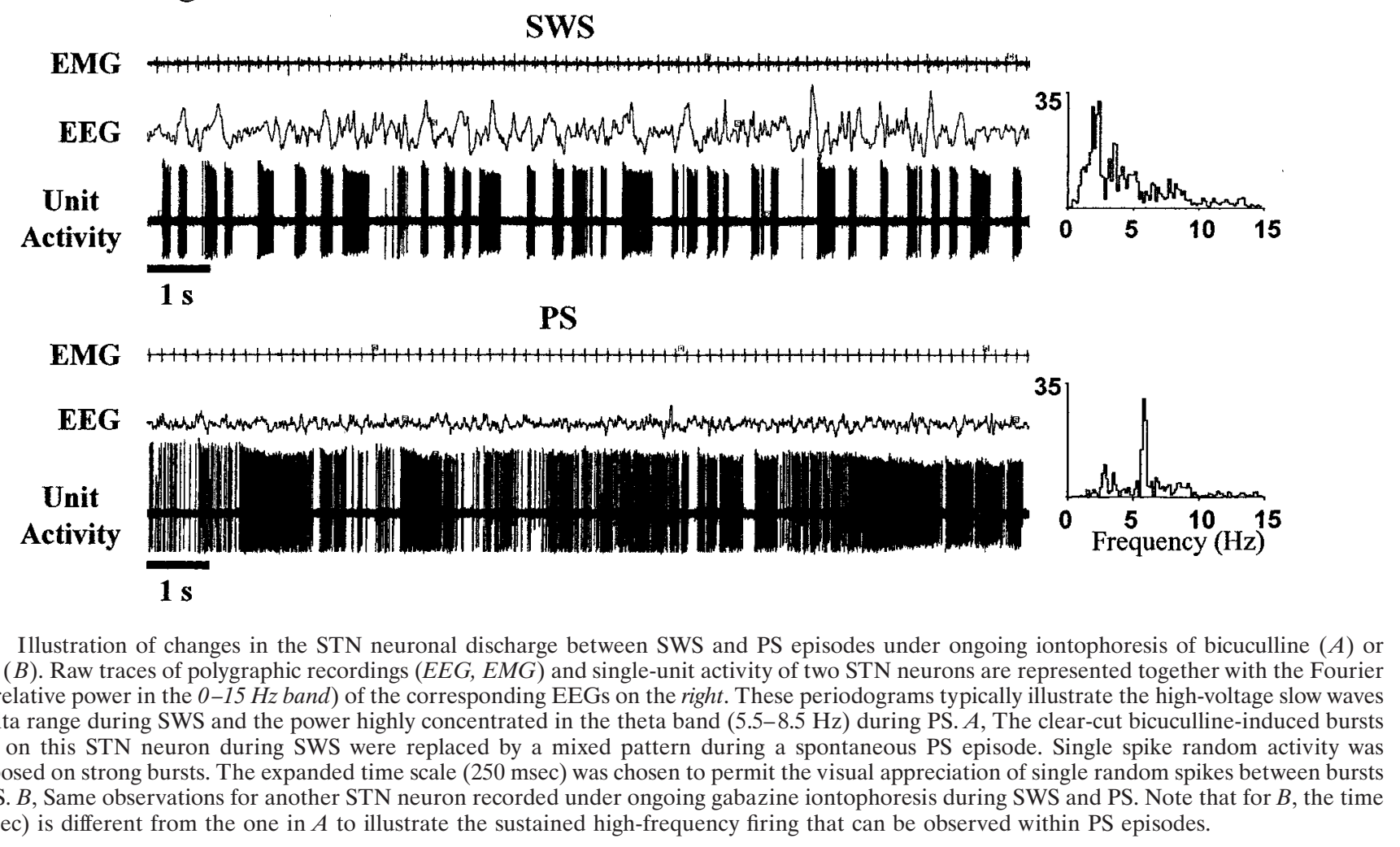

Figure 8. Illustration of changes in the STN neuronal discharge between SWS and PS episodes under ongoing iontophoresis of bicuculline ( $A$ ) or gabazine $(B)$. Raw traces of polygraphic recordings $(E E G, E M G)$ and single-unit activity of two STN neurons are represented together with the Fourier spectra (relative power in the $0-15 \mathrm{~Hz}$ band) of the corresponding EEGs on the right. These periodograms typically illustrate the high-voltage slow waves in the delta range during SWS and the power highly concentrated in the theta band $(5.5-8.5 \mathrm{~Hz})$ during PS. $A$, The clear-cut bicuculline-induced bursts recorded on this STN neuron during SWS were replaced by a mixed pattern during a spontaneous PS episode. Single spike random activity was superimposed on strong bursts. The expanded time scale $(250 \mathrm{msec})$ was chosen to permit the visual appreciation of single random spikes between bursts during PS. $B$, Same observations for another STN neuron recorded under ongoing gabazine iontophoresis during SWS and PS. Note that for $B$, the time scale $(1 \mathrm{sec})$ is different from the one in $A$ to illustrate the sustained high-frequency firing that can be observed within PS episodes.

tized rats (Féger et al., 1991). Taken together, our findings on a nonanesthetized preparation suggest that STN cell bodies (but also axons; Nowak and Bullier, 1998a,b) may easily follow frequencies considerably $>130 \mathrm{~Hz}$ (clinical effective frequency). Although today there is no evidence that such high firing rates can be maintained for a particularly long time and whether it is possible to faithfully transmit increases in glutamatergic firing to postsynaptic targets for an extended period, these data nevertheless challenge somewhat the "depolarization block" hypothesis. These results might support alternative mechanisms for deep brain stimulation in PD (Ashby et al., 1999, 2001; Windels et al., 2000), in particular the regularization of firing pattern of STN targets, as suggested recently (Hashimoto et al., 2001).

\section{REFERENCES}

Afsharpour S (1985) Topographical projections of the cerebral cortex to the subthalamic nucleus. J Comp Neurol 236:14-28.

Akaoka H, Charléty P, Saunier CF, Buda M, Chouvet G (1992) Inhibition of nigral dopamine neurons by systemic and local apomorphine: possible contribution of dendritic autoreceptors. Neuroscience 49:879-891. 
Albin RL, Young AB, Penney JB (1989) The functional anatomy of basal ganglia disorders. Trends Neurosci 12:366-374.

Albin RL, Young AB, Penney JB (1995) The functional anatomy of disorders of the basal ganglia. Trends Neurosci 18:63-64.

Ashby P, Kim YJ, Kumar R, Lang AE, Lozano AM (1999) Neurophysiological effects of stimulation trough electrodes in the human subthalamic nucleus. Brain 122:1919-1931.

Ashby P, Paradiso G, Saint-Cyr JA, Chen R, Lang AE, Lozano AE (2001) Potentials recorded at the scalp by stimulation near the human subthalamic nucleus. Clin Neurophysiol 112:431-437.

Baufreton J, Garret M, Dovero S, Dufy B, Bioulac B, Taupignon A (2001) Activation of $\mathrm{GABA}_{\mathrm{A}}$ receptors in subthalamic neurons in vitro: properties of native receptors and inhibition mechanisms. J Neurophysiol 86:75-85.

Bell K, Churchill L, Kalivas PW (1995) GABAergic projection from the ventral pallidum and globus pallidus to the subthalamic nucleus. Synapse 20:10-18

Benabid AL, Pollak P, Gross C, Hoffman D, Benazzouz A, Gao DM, Laurent A, Gentil M, Perret J (1994) Acute and long-term effects of subthalamic nucleus stimulation in Parkinson's disease. Stereotact Funct Neurosurg 62:76-84.

Benazzouz A, Gross C, Féger J, Boraud T, Bioulac B (1993) Reversal of rigidity and improvement in motor performance by subthalamic highfrequency stimulation in MPTP-treated monkeys. Eur J Neurosci $5: 382-389$.

Benazzouz A, Piallat B, Pollak P, Benabid AL (1995) Responses of substantia nigra pars reticulata and globus pallidus complex to high frequency stimulation of the subthalamic nucleus in rats: electrophysiological data. Neurosci Lett 189:77-80.

Benazzouz A, Boraud T, Féger J, Burbaud P, Bioulac B, Gross C (1996) Alleviation of experimental hemiparkinsonism by high-frequency stimulation of the subthalamic nucleus in primates: a comparison with L-dopa treatment. Mov Disord 11:627-632.

Benazzouz A, Gao DM, Ni GZ, Piallat B, Boualli-Benazzouz R, Benabid AL (2000) Effect of hih-frequency stimulation of the subthalamic nucleus on the neuronal activities of the substantia nigra pars reticulata and ventrolateral nucleus of the thalamus in the rat. Neuroscience 99:289-295.

Bergman H, Wichmann T, DeLong MR (1990) Reversal of experimental parkinsonism by lesions of the subthalamic nucleus. Science 249:1436-1438.

Bergman H, Wichmann T, Karmon B, DeLong MR (1994) The primate subthalamic nucleus. II. Neuronal activity in the MPTP model of parkinsonism. J Neurophysiol 72:507-520.

Bergman H, Raz A, Feingold A, Nini A, Nelken I, Hansel D, Benpazi H, Reches A (1998) Physiology of MPTP tremor. Mov Disord 13:29-34.

Beurrier C, Bézard E, Bioulac B, Gross C (1997) Subthalamic stimulation elicits hemiballismus in normal monkey. NeuroReport 8:1625-1629.

Beurrier C, Congar P, Bioulac B, Hammond C (1999) Subthalamic nucleus neurons switch from single-spike activity to burst-firing mode. J Neurosci 19:599-609.

Bevan MD, Bolam JP (1995) Cholinergic, GABAergic, and glutamateenriched inputs from the mesopontine tegmentum to the subthalamic nucleus in the rat. J Neurosci 15:7105-7120.

Bevan MD, Wilson CJ (1999) Mechanisms underlying spontaneous oscillation and rhythmic firing in rat subthalamic neurons. J Neurosci 19:7617-7628.

Bevan MD, Francis CM, Bolam JP (1995) The glutamate-enriched cortical and thalamic input to neurons in the subthalamic nucleus of the rat: convergence with GABA-positive terminals. J Comp Neurol 361:491-511.

Bevan MD, Clarke NP, Bolam JP (1997) Synaptic integration of functionally diverse pallidal information in the entopeduncular nucleus and subthalamic nucleus in the rat. J Neurosci 17:308-324.

Bevan MD, Wilson CJ, Bolam JP, Magill PJ (2000) Equilibrium potential of GABA(A) current and implications for rebound burst firing in rat subthalamic neurons in vitro. J Neurophysiol 83:3169-3172.

Bevan MD, Magill PJ, Hallworth NE, Bolam JP, Wilson CJ (2002) Regulation of the timing and pattern of action potential generation in rat subthalamic neurons in vitro by GABA-A IPSPs. J Neurophysiol 87:1348-1362.

Booth PAC, Bolam JP, Ige AO, Disney GH, Marshall FH, White JH, Emson PC (2000) GABAB receptors in the rat brain: cellular and subcellular distribution in the basal ganglia. Eur J Neurosci 12:133.

Burbaud P, Gross C, Bioulac B (1994) Effect of subthalamic high frequency stimulation on substantia nigra pars reticulata and globus pallidus neurons in normal rats. J Physiol (Paris) 88:359-361.

Canteras NS, Shammah-Lagnado SJ, Silva BA, Ricardo JA (1990) Afferent connections of the subthalamic nucleus: a combined retrograde and anterograde horseradish peroxidase study in the rat. Brain Res 513:43-59.

Charara A, Heilman TC, Levey AI, Smith Y (2000) Pre- and postsynaptic localization of GABA(B) receptors in the basal ganglia in monkeys. Neuroscience 95:127-140.
Cheruel F, Dormont JF, Farin D (1996) Activity of neurons of the subthalamic nucleus in relation to motor performance in the cat. Exp Brain Res 108:206-220.

Contreras D, Steriade M (1997a) Synchronization of low-frequency rhythms in corticothalamic networks. Neuroscience 76:11-24.

Contreras D, Steriade M (1997b) State-dependent fluctuations of lowfrequency rhythms in corticothalamic networks. Neuroscience 76:25-38.

Crossman AR, Sambrook MA, Jackson A (1980) Experimental hemiballismus in the baboon produced by injection of a gammaaminobutyric acid antagonist into the basal ganglia. Neurosci Lett 20:369-372.

Crossman AR, Sambrook MA, Jackson A (1984) Experimental hemichorea/hemiballismus in the monkey. Studies on the intracerebral site of action in a drug-induced dyskinesia. Brain 107:579-596.

Darracq L, Gervasoni D, Soulière F, Lin JS, Fort P, Chouvet G, Luppi PH (1996) Effect of strychnine on rat locus coeruleus neurones during sleep and wakefulness. NeuroReport 8:351-355.

Debarbieux F, Brunton J, Charpak S (1998) Effect of bicuculline on thalamic activity: a direct blockade of IAHP in reticularis neurons. J Neurophysiol 79:2911-2918.

DeLong MR (1990) Primate models of movement disorders of basal ganglia origin. Trends Neurosci 13:281-285.

DeLong MR, Crutcher MD, Georgopoulos AP (1985) Primate globus pallidus and subthalamic nucleus: functional organization. J Neurophysiol 53:530 -543 .

Féger J, Robledo P, Renwart N (1991) The subthalamic nucleus: new data, new questions. In: The basal ganglia III (Bernardi G, Carpentier MB, Di Chiara G, Morelli M, Stanzione P, eds), pp 99-108. New York: Plenum.

Féger J, Bevan M, Crossman AR (1994) The projections from the parafascicular thalamic nucleus to the subthalamic nucleus and the striatum arise from separate neuronal populations: a comparison with the corticostriatal and corticosubthalamic efferents in a retrograde fluorescent double-labelling study. Neuroscience 60:125-132.

Fujimoto K, Kita H (1993) Response characteristics of subthalamic neurons to the stimulation of the sensorimotor cortex in the rat. Brain Res 609:185-192.

Gervasoni D, Darracq L, Fort P, Soulière F, Chouvet G, Luppi PH (1998) Electrophysiological evidence that noradrenergic neurons of the rat locus coeruleus are tonically inhibited by GABA during sleep. Eur J Neurosci 10:964-970.

Gervasoni D, Peyron C, Rampon C, Barbagli B, Chouvet G, Urbain N, Fort P, Luppi PH (2000) Role and origin of the GABAergic innervation of dorsal raphe serotonergic neurons. J Neurosci 20:4217-4225.

Hamann M, Desarmenien M, Desaulles E, Bader MF, Feltz P (1988) Quantitative evaluation of the properties of a pyridazinyl GABA derivative (SR 95531) as a GABAA competitive antagonist. An electrophysiological approach. Brain Res 442:287-296.

Hammond C, Féger J, Bioulac B, Souteyrand JP (1979) Experimental hemiballism in the monkey produced by unilateral kainic acid lesion in corpus Luysii. Brain Res 171:577-580.

Hammond C, Rouzaire-Dubois B, Féger J, Jackson A, Crossman AR (1983) Anatomical and electrophysiological studies on the reciprocal projections between the subthalamic nucleus and nucleus tegmenti pedunculopontinus in the rat. Neuroscience 9:41-52

Hassani OK, Mouroux M, Féger J (1996) Increased subthalamic neuronal activity after nigral dopaminergic lesion independent of disinhibition via the globus pallidus. Neuroscience 72:105-115.

Hashimoto T, Elder CM, DeLong MR, Vitek JL (2001) Responses of pallidal neurons to electrical stimulation of the subthalamic nucleus in experimental parkinsonism. Soc Neurosci Abstr 27:1994.

Heaulme M, Chambo JP, Leyris R, Molimard JC, Wermuth CG, Bizière K (1986) Biochemical characterization of the interaction of three pyridazinyl-GABA derivatives with the GABAA receptor site. Brain Res 384:224-231.

Hollerman JR, Grace AA (1992) Subthalamic nucleus cell firing in the 6-OHDA-treated rat: basal activity and response to haloperidol. Brain Res 590:291-299.

Johnson SW, Seutin V (1997) Bicuculline methiodide potentiates NMDA-dependent burst firing in rat dopamine neurons by blocking apamin-sensitive $\mathrm{Ca}^{2+}$-activated $\mathrm{K}^{+}$currents. Neurosci Lett 231:13-16.

Kaneoke Y, Vitek JL (1996) Burst and oscillation as disparate neuronal properties. J Neurosci Methods 68:211-223.

Khawaled R, Bruening-Wright A, Adelman JP, Maylie J (1999) Bicuculline block of small-conductance calcium-activated potassium channels. Pflügers Arch 438:314-321.

Kita H (1994) Parvalbumin-immunopositive neurons in rat globus pallidus: a light and electron microscopic study. Brain Res 657:31-41.

Kita H, Chang HT, Kitai ST (1983) Pallidal inputs to subthalamus: intracellular analysis. Brain Res 264:255-265.

Kitai ST, Deniau JM (1981) Cortical inputs to the subthalamus: intracellular analysis. Brain Res 214:411-415.

Kitai ST, Kita H (1987) Anatomy and physiology of the subthalamic 
nucleus: a driving force of the basal ganglia. In: The basal ganglia II: structure and function (Carpenter MB, Jayavaman A, eds), pp 357-373. New York: Plenum.

Kreiss DS, Anderson LA, Walters JR (1996) Apomorphine and dopamine D-1 receptor agonists increase the firing rates of subthalamic nucleus neurons. Neuroscience 72:863-876.

Kreiss DS, Mastropietro CW, Rawji SS, Walters JR (1997) The response of subthalamic nucleus neurons to dopamine receptor stimulation in a rodent model of Parkinson's disease. J Neurosci 17:6807-6819.

Legendy CR, Salcman M (1985) Bursts and recurrence of bursts in the spike trains of spontaneously active striate cortex neurons. J Neurophysiol 53:926-939.

Levy R, Hutchison WD, Lozano AM, Dostrovsky JO (2000) Highfrequency synchronization of neuronal activity in the subthalamic nucleus of parkinsonian patients with limb tremor. J Neurosci 20:77667775 .

Limousin P, Pollak P, Benazzouz A, Hoffmann D, Broussolle E, Perret JE, Benabid AL (1995a) Bilateral subthalamic nucleus stimulation for severe Parkinson's disease. Mov Disord 10:672-674.

Limousin P, Pollak P, Benazzouz A, Hoffmann D, Le Bas JF, Broussolle E, Perret JE, Benabid AL (1995b) Effect on parkinsonian signs and symptoms of bilateral subthalamic nucleus stimulation. Lancet 345:91-95.

Magariñoz-Ascone CM, Figueiras-Mendez R, Riva-Meana C, CordobaFernandez A (2000) Subthalamic neuron activity related to tremor and movement in Parkinson's disease. Eur J Neurosci 12:2597-2607.

Magill PJ, Bolam JP, Bevan MD (2000) Relationship of activity in the subthalamic nucleus-globus pallidus network to cortical electroencephalogram. J Neurosci 20:820-833.

Magill PJ, Bolam JP, Bevan MD (2001) Dopamine regulates the impact of the cerebral cortex on the subthalamic nucleus-globus pallidus network. Neuroscience 106:313-330.

Matsumura M, Kojima J, Gardiner TW, Hikosaka O (1992) Visual and oculomotor functions of monkey subthalamic nucleus. J Neurophysiol 67:1615-1632.

McCormick DA, Bal T (1997) Sleep and arousal: thalamocortical mechanisms. Annu Rev Neurosci 20:185-215.

Mestdagh N, Wulfert E (1999) Bicuculline increases $\mathrm{Ca}^{2+}$ transients in rat cerebellar granule cells through non-GABA(A) receptor associated mechanisms. Neurosci Lett 265:95-98.

Michaud JC, Mienville JM, Chambon JP, Bizière K (1986) Interactions between three pyridazinyl-GABA derivatives and central GABA and glycine receptors in the rat, an in vivo microiontophoretic study. Neuropharmacology 25:1197-1203.

Mienville JM, Vicini S (1987) A pyridazinyl derivative of gammaaminobutyric acid (GABA), SR 95531, is a potent antagonist of Clchannel opening regulated by GABAA receptors. Neuropharmacology 26:779-783.

Miller JJ, McLennan (1974) The action of bicuculline upon acetylcholineinduced excitations of central neurones. Neuropharmacology 13:785787.

Mink JW, Thach WT (1993) Basal ganglia intrinsic circuits and their role in behavior. Curr Opin Neurobiol 3:950-957.

Moriizumi T, Hattori T (1992) Separate neuronal populations of the rat globus pallidus projecting to the subthalamic nucleus, auditory cortex and pedunculopontine tegmental area. Neuroscience 46:701-710.

Mouroux M, Féger J (1993) Evidence that the parafascicular projection to the subthalamic nucleus is glutamatergic. NeuroReport 4:613-615.

Mouroux M, Hassani OK, Féger J (1995) Electrophysiological study of the excitatory parafascicular projection to the subthalamic nucleus and evidence for ipsi- and contralateral controls. Neuroscience 67:399-407.

Mouroux M, Hassani OK, Féger J (1997) Electrophysiological and Fos immunohistochemical evidence for the excitatory nature of the parafascicular projection to the globus pallidus. Neuroscience 81:387-397.

Nakanishi, Kita H, Kitai ST (1987) Electrical membrane properties of rat subthalamic neurons in an in vitro slice preparation. Brain Res 437:35-44

Nakao N, Ogura M, Nakai K, Itakura T (1998) Intrastriatal mesencephalic grafts affect neuronal activity in basal ganglia nuclei and their target structures in a rat model of Parkinson's disease. J Neurosci 18:1806-1817.

Ng TKY, Yung KKL (2001) Cellular localization of $\mathrm{GABA}_{\mathrm{B}}$ receptors in the rat subthalamic nucleus. Soc Neurosci Abstr 27:764.

Nowak LG, Bullier J (1998a) Axons, but not cell bodies, are activated by electrical stimulation in cortical grey matter. I. Evidence from chronaxie measurements. Exp Brain Res 118:477-488.

Nowak LG, Bullier J (1998b) Axons, but not cell bodies, are activated by electrical stimulation in cortical gray matter. II. Evidence from selective inactivation of cell bodies and axon initial segments. Exp Brain Res 118:489-500

Overton PG, Greenfield SA (1995) Determinants of neuronal firing pattern in the guinea-pig subthalamic nucleus: an in vivo and in vitro comparison. J Neural Transm Park Dis Dement Sect 10:41-54.

Paxinos G, Watson W (1996) The rat brain in stereotaxic coordinates. Sydney: Academic.
Périer C, Agid Y, Hirsch EC, Féger J (2000) Ipsilateral and contralateral subthalamic activity after unilateral dopaminergic lesion. NeuroReport 11:3275-3278

Plenz D, Kitai ST (1999) A basal ganglia pacemaker formed by the subthalamic nucleus and external globus pallidus. Nature 400:677-682

Rodriguez MC, Guridi OJ, Alvarez L, Mewes K, Macias R, Vitek J, Delong MR, Obeso JA (1998) The subthalamic nucleus and tremor in Parkinson's disease. Mov Disord 13:111-118.

Rognan D, Boulanger T, Hoffmann R, Vercauteren DP, Andre JM, Durant F, Wermuth CG (1992) Structure and molecular modeling of GABAA receptor antagonists. J Med Chem 35:1969-1977.

Rouzaire-Dubois B, Hammond C, Hamon B, Féger J (1980) Pharmacological blockade of the globus pallidus-induced inhibitory response of subthalamic cells in the rat. Brain Res 200:321-329.

Ryan LJ, Clark KB (1992) Alteration of neuronal responses in the subthalamic nucleus following globus pallidus and neostriatal lesions in rats. Brain Res Bull 29:319-327.

Ryan LJ, Sanders DJ, Clark KB (1992) Auto- and cross-correlation analysis of subthalamic nucleus neuronal activity in neostriatal- and globus pallidal-lesioned rats. Brain Res 583:253-261.

Schwarzer C, Berresheim U, Pirker S, Wieselthaler A, Fuchs K, Sieghart W, Sperk G (2001) Distribution of the major gamma-aminobutyric acid (A) receptor subunits in the basal ganglia and associated limbic areas of the adult rat. J Comp Neurol 433:526-549.

Seutin V, Scuvée-Moreau J, Dresse A (1997) Evidence for a nonGABAergic action of quaternary salts of bicuculline on dopaminergic neurones. Neuropharmacology 36:1653-1657.

Shen KZ, Johnson SW (2001) Presynaptic GABA receptors inhibit synaptic inputs to rat subthalamic neurons. Neuroscience 108:431-436.

Smith Y, Bolam JP, Von Krosigk M (1990) Topographical and synaptic organisation of the GABA-containing pallidosubthalamic projection in the rat. Eur J Neurosci 2:500-511.

Soulière F, Urbain N, Gervasoni D, Schmitt P, Guillemort C, Fort P, Renaud B, Luppi PH, Chouvet G (2000) Single-unit and polygraphic recordings associated with systemic or local pharmacology: a multipurpose stereotaxic approach for the awake, anaesthetic-free, and head-restrained rat. J Neurosci Res 61:88-100.

Steriade M (1993) Central core modulation of spontaneous oscillations and sensory transmission in thalamocortical systems. Curr Opin Neurobiol 3:619-625.

Steriade M, McCormick DA, Sejnowski TJ (1993) Thalamocortical oscillations in the sleeping and aroused brain. Science 262:679-685.

Stone TW (1985) Microiontophoresis and pressure ejection. New York: Wiley.

Svenneby G, Roberts E (1973) Bicuculline and $N$-methylbicuculline: competitive inhibitors of brain acetylcholinesterase. $\mathrm{J}$ Neurochem 21:1025-1026

Urbain N, Gervasoni D, Soulière F, Lobo L, Rentéro N, Windels F, Astier B, Savasta M, Fort P, Renaud B, Luppi PH, Chouvet G (2000) Unrelated course of subthalamic nucleus and globus pallidus neurona activities across vigilance states in the rat. Eur J Neurosci 12:3361-3374

Van der Kooy D, Kolb B (1985) Non-cholinergic globus pallidus cells that project to the cortex but not to the subthalamic nucleus in rat. Neurosci Lett 57:113-118.

Van der Kooy D, Hattori T, Shannak K, Hornikiewicz O (1981) The pallido-subthalamic projection in rat: anatomical and biochemical studies. Brain Res 204:253-268.

Vila M, Périer C, Féger J, Yelnik J, Faucheux B, Ruberg M, RaismanVozri R, Agid Y, Hirsch EC (2000) Evolution of changes in neurona activity in the subthalamic nucleus of rats with unilateral lesion of the substantia nigra assessed by metabolic and electrophysiological measurements. Eur J Neurosci 12:337-344.

Wichmann T, Bergman H, DeLong MR (1994a) The primate subthalamic nucleus. I. Functional properties in intact animals. J Neurophysiol 72:494-506

Wichmann T, Bergman H, DeLong MR (1994b) The primate subthalamic nucleus. III. Changes in motor behavior and neuronal activity in the internal pallidum induced by subthalamic inactivation in the MPTP model of parkinsonism. J Neurophysiol 72:521-530.

Wigmore MA, Lacey MG (2000) A Kv3-like persistent, outwardly rectifying, $\mathrm{Cs}^{+}$-permeable, $\mathrm{K}^{+}$current in rat subthalamic nucleus neurones. J Physiol (Lond) 527:493-506.

Windels F, Bruet N, Poupard A, Urbain N, Chouvet G, Feuerstein C, Savasta M (2000) Effects of high frequency stimulation of subthalamic nucleus on extracellular glutamate and GABA in substantia nigra and globus pallidus in the normal rat. Eur J Neurosci 12:4141-4146.

Wisden W, Laurie DJ, Monyer H, Seeburg PH (1992) The distribution of 13 GABAA receptor subunits mRNAs in the rat brain. I. Telencephalon, diencephalon, mesencephalon. J Neurosci 12:1040-1062.

Yu S, Ho IK (1990) Effects of GABA antagonists, SR 95531 and bicuculline, on GABAA receptor-regulated chloride flux in rat cortical synaptoneurosomes. Neurochem Res 15:905-910.

Zhang JH, Araki T, Sato M, Toyama M (1991) Distribution of GABAA-receptor alpha 1 subunit gene expression in the rat forebrain. Brain Res Mol Brain Res 11:239-247. 